\section{A COMPUTING CHART FOR MAKING A DIF- FERENTIAL LEUCOCYTE COUNT}

$$
\begin{aligned}
& \text { A. E. OSMOND, M.D } \\
& \text { CINCINNATI }
\end{aligned}
$$

Any laboratory worker who has had any amount of blood work to do, especially in making differential leucocyte counts, has been more or less troubled with the necessity of having to figure out the percentages of the various types of cells and the liability of error.

The accompanying chart I have devised for use in the laboratory of the Cincinnati Hospital, and we have found it quite convenient in simplifying the work and removing sources of error. The chart is inexpensive and can be made out of a piece of ground glass or a slate, suitably ruled and marked in ink so as to be permanent. The temporary markings are made in pencil, can be readily erased, and the chart is again ready for service.

It is figured out on a basis of a count of two hundred leucocytes, and marked on the left to designate the various types of cells, as polymorphonuclear, large lymphocytes, small lymphocytes, eozinophiles, transitional cells, ete. At the bottom are the calculated percentages, and at the top the actual number of cells counted when the vertical columns are filled.

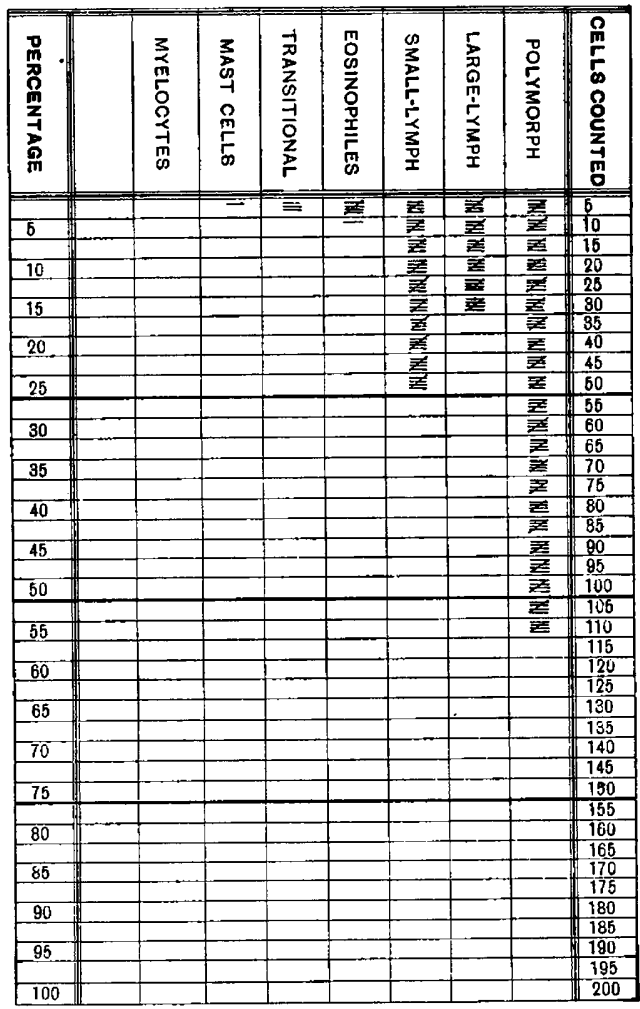

A computing chart to facilitate making a differential leucocyte estimaticn.

The heavy lines running vertically are put in simply to facilitate the count, by indicating when fifty, one hundred or one hundred and fifty units are counted for a certain type of cell, and by referring to the figures in the top row one can at once read off the actual number of each type of cell counted, and easily sum up when a total of two hundred has been reached.

This being done, the percentages are read off directly from the bottom figures and the usual calculating with the possibility of error is entirely removed.

19 West Seventh Street.

\section{A NEW ANAL SPECULUM DUDLEY ROBERTS, M.D. BROOKLYN}

The speculum here described was constructed in the hope of securing an anal speculum which could be introduced into a hypersensitive anus without causing much pain. The object has been accomplished, for, from a considerable experience with its use, I have found that even an anus which is the seat of an irritable ulcer tolerates examination with this instrument in a most surprising manner.

It has also been found that the view of the mucosa is exceedingly satisfactory. The distention is equilateral and no distortion of parts is occasioned, as is the case

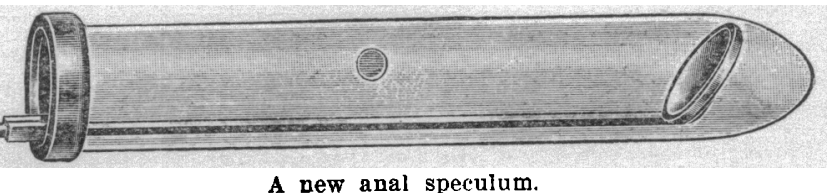

when the parts are made to present at the end of a tubular speculum or when some form of dilating speculum is used. It is possible that this instrument may facilitate the discovery of the mouth of a fistulous opening. Hemorrhoids are seen as bluish spots, and a far more accurate conception is obtained as to their number and size than when the patient forces down the entire venous tissue of the anal region by straining.

The tube is made of a glass of suitable thickness and the greatest possible clearness. The hole in the side of the tube is introduced for the possible purpose of making applications to ulcerated surfaces and the probing of spots suggestive of fistula. The mirror, which gives the view of the anal wall, is so arranged that it can be pushed in or withdrawn and also rotated showing the entire surface of the anus at different depths. Lubrication of the tube before introduction is done with a translucent lubricant, such as glycerin, or one of the proprietary preparations made for that purpose.

It is necessary to use either reflected light from a head-mirror or an electric head-light. When light such as this is thrown on the mirror the view is remarkably distinct, but ordinary diffuse light does not serve the purpose.

84 Remsen Street.

\section{TRANSIENT PRESENCE OF CAS'TS IN URINE OF HEALTHY INFANTS}

\section{MILTON GOLDSMITH, M.D.} PITTSBURG, PA.

In connection with the article on "Transitory Urinary Findings Associated with Some Diseases of Childhood," by Carr, I wish to report the following case:

A male child, 11/2 months old, breast-fed until 9 months, had been since then on gradually increasing quantities of cow's milk, with cereals and corresponding withdrawal of breastmilk, until at the time these observations were made the child could be considered practically weaned.

This baby was larger than the average for his age, was strong and muscular, of a very happy disposition, had never been sick, and from all points of view would be considered an ideai child. I was attending another member of the family and simply out of curiosity to know something of the urinary

1. Carr, W. L. : The Jourval A. M. A., Nov. 13, 1909, liii, 1622. 